\title{
Beitrag zur Frage nach der Assimilation des Nahrungseiweilß im tierischen Organismus.
}

\author{
Von \\ Emil Abderhalden und Franz Samuely. \\ (Aus dem I. Chemischen Institut der Universität Berlin.) \\ (Der Redaktion zugegangen am 21. August 1905.)
}

Die Untersuchungen aus dem hiesigen Institute über die Zusammensetzung der Eiweißkörper haben gezeigt, daß die den verschiedenartigsten Gruppen angehörenden Eiweißarten qualitativ sehr ähnlich, ja sogar, soweit unsere Kenntnisse reichen, gleich aufgebaut sind. Quantitativ dagegen sind die einzelnen Bausteine in den verschiedenen Eiweißarten recht verschieden vertreten. Der eine von uns ${ }^{1}$ ) hat jüngst aus diesen Tatsachen unter Hinweis auf die Zusammensetzung der Eiweißkörper der Nahrung und derjenigen des Körpers selbst, speziell des Serums, den Schluß gezogen, daß an irgend einer Stelle im Organismus weitgehende Umwandlungen sich vollziehen müssen, um das Nahrungseiweiß in «Körpereiweiß» umzuwandeln. Nun findet im Darmkanal unter der Einwirkung der Pankreasfermente offenbar ein viel bedeutenderer Abbau des Eiweißes statt, als man bis jetzt annahm. Die Möglichkeit, daß das Eiweiß der Nahrung bereits im Darmkanal selbst weit abgebaut wird, um dann sofort nach der Resorption wieder aufgebaut zu werden, hat nach neueren Beobachtungen viel Wahrscheinlichkeit für sich. Dafür sprechen auch die von dem einen von uns in Gemeinschaft mit P. Rona ${ }^{2}$ ) ausgeführten Versuche, bei denen es gelang, einen Hund durch lange Zeit hindurch mit sehr weit abgebautem Eiweiß im Stickstoffgleichgewicht zu behalten. Wir haben jedoch bei der Mitteilung dieser Untersuchung schon damals betont, daß jene Versuche nicht ohne weiteres für einen nor-

1) Emil Abderhalden, Abbau und Aufbau der Eiweißkörper im tierischen Organismus, Diese Zeitschrift, Bd. XLIV, S. 17, 1905.

2) Emil Abderhalden und Peter Rona, Über die Verwertung der Abbauprodukte des Caseins im tierischen Organismus, Diese Zeitschrift, Bd. XLIV, S. 198, 1905.

Hoppe-Seyler's Zeitschrift f. physiol, Chemie. XLVI. 
malerweise stattfindenden, weitgehenden Eiweißabbau sprechen. Es wäre wohl möglich, daß die Fermenthydrolyse unter normalen Umständen nur wenig weit geht, und es jeder einzelnen Körperzelle überlassen bliebe, aus dem «zirkulierenden» Eiweiß des Blutes «ihr» Eiweiß sich zu bilden. Daß im Blutserum im allgemeinen kein körperfremdes Eiweiß vorhanden ist, das haben die Versuche mit Hilfe der biologischen Reaktion bewiesen. Wie weit jedoch "Nahrungseiweiß» umgewandelt sein muß, um die betreffende Reaktion nicht mehr zu geben, darüber fehlt uns jede Einsicht und wird uns solange fehlen, bis auch hier die synthetischen Produkte, die Peptide, die Entscheidung bringen werden.

Wir legten uns nun die Frage vor, ob das "Serumeiweiß" eine ganz bestimmte einheitliche Gruppe von Eiweißkörpern darstellt, oder aber, ob es ganz direkt von Nahrungseiweiß abhängig ist. Dies mußte sich durch folgenden Versuch entscheiden lassen. Wir entzogen, wie das untenstehende Versuchsprotokoll zeigt, einem Pferde einen großen Teil seiner Bluteiweißkörper, ließen dann das Versuchstier hungern und entzogen ihm aufs neue Blut. Nun fütterten wir das Tier mit einem Eiweißkörper, der eine ganz andere Zusammensetzung besaß als das "gewöhnliche» Serumeiweiß. Wir wählten das Gliadin aus Weizenmehl, das nach unseren Untersuchungen $\left.31,5,{ }^{1}\right)$ nach nochmals sorgfältig wiederholten Bestimmungen 36, $\tilde{0} \%$ Glutaminsäure enthält, während Serumglobulin des Pferdes nach drei neuen Bestimmungen nur 8,5\% und Serumalbumin $7,7 \%$ Glutaminsäure besitzt. Die Tyrosinbestimmung des verwendeten Gliadins ergab 2,37\%. Wir bestimmten nun den Tyrosin- und Glutaminsäuregehalt der «normalen » Serumeiweißkörper, dann dieselben Werte im «Hungerserum», und schließlich untersuchten wir die Serumeiweißkörper nach sehr ausgiebiger Gliadinfütterung und hofften auf diese Weise zu erfahren, ob «Gliadin» resp. ein gliadinähnliches, d. h. ein an Glutaminsäure reicheres Eiweiß im Serum nachzuweisen ist.

Wir waren uns zum vornherein sehr wohl bewußt, daß gegen unsere Versuchsanordnung zahlreiche Einwände möglich

1) Die Zusammensetzung des «Gliadins aus Weizenmehl, Diese Zeitschrift, Bd. XLIV, S. 283, 1905. 
sind. Einmal können die resorbierten Partien so klein sein und so rasch weiter verarbeitet werden, daß sie unserem immerhin nicht sehr empfindlichen Nachweis entgingen. Wir hatten ja unter allen Umständen mit einem stark «verdünnten» Gliadin zu rechnen, denn die «alten» Serumeiweißkörper waren ja zum Teil wenigstens auch noch vorhanden. Dagegen hatten wir dem Versuchstiere so große Quantitäten von Blut entzogen und so reichlich Gliadin eingeführt, daß doch zu erwarten war, daß die mindestens dreimal größere Glutaminsäuremenge des Gliadins doch eine deutlich nachweisbare Zunahme des Glutaminsäuregehaltes bedingen würde. Viel wichtiger ist der Einwand, daß wir nur das Blut jenseits der Leber untersucht haben. Es wäre immerhin möglich, daß die Eiweißkörper des Pfortaderblutserums verändert waren. Wir hoffen, nach unseren jetzigen Untersuchungen in die Lage zu kommen, diese Versuche noch ausführen zu können, um so den Ort der Eiweißsynthese oder genauer und umfassender der Eiweißassimilation exakter festlegen zu können. Man könnte auch den Einwand erheben, daß das «Serumeiweiß» kein «einheitliches * Eiweiß, sondern sicher ein Gemenge ist. Es wäre wohl wünschenswert gewesen, Serumglobulin und Serumalbumin für sich allein zu untersuchen. Wir haben vorläufig auf diesen Versuch verzichtet, weil es uns momentan nur darauf ankam, festzustellen, ob überhaupt eine Veränderung zu konstatieren war. Da außerdem Serumalbumin und Serumglobulin einen sehr ähnlichen Glutaminsäuregehalt besitzen, konnten Schwankungen in ihren Mengenverhältnissen unsere Resultate nur wenig beeinflussen.

Was die angewandte Methodik anbetrifft, so ist folgendes zu bemerken. Der bei $100^{\circ}$ getrocknete Eiweißkörper wurde genau gewogen, dann mit 25\% \%iger Schwefelsäure 16 Stunden am Rückflußkühler gekocht, die Schwefelsäure quantitativ mit Baryt entfernt, der Baryumsulfatniederschlag solange mit heißem Wasser ausgekocht, bis eine Probe des Filtrates keine Spur einer Reaktion mit Millons Reagens gab. Jede Versuchsserie wurde gemeinsam verarbeitet. Die Flüssigkeitsmengen, die zum Auskochen der Niederschläge verwendet wurden, waren dieselben, kurz es wurde stets in genau derselben Weise bei allen 
Portionen vorgegangen. Die vereinigten Flüssigkeiten der ein-zelnen Portionen wurden nun mit Tierkohle gründlich auf-gekocht, und das hellgelb gefärbte Filtrat solange eingeengt, bis alles Tyrosin abgeschieden war. Hierbei muß sorgfältig; vermieden werden, daß nicht Glutaminsäure mit auskristallisiert. . Sie ist jedoch in kleinsten Mengen durch ihren ganz eigen-tümlich sauren und zugleich etwas adstringierenden Geschmack : leicht $\mathrm{zu}$ erkennen. Das so gewonnene Tyrosin wurde noch-mals aus heißem Wasser umkristallisiert und nun gewogen.

Die Mutterlauge vom Tyrosin wurde nun nochmals energisch । mit Tierkohle behandelt, bis die Flüssigkeit nur noch hellgelb, gefärbt war. Es ist für die quantitative Abscheidung der Glutaminsäure als Chlorhydrat von sehr großer Wichtigkeit, daß die: Lösung fast farblos ist. In die Flüssigkeit wurde nun, nachdem sie auf ein kleines Volumen gebracht war, gasförmige Salzsäure bis zur Sättigung eingeleitet und nunmehr ein Kriställchen von Glutaminsäurechlorhydrat eingeimpft. Beim Stehen auf Eis über Nacht hatte sich die ganze Flüssigkeitsmenge stets in einen dicken Kristallbrei verwandelt, der sich sehr rasch auf Koliertuch auf der Nutsche absaugen und scharf abpressen ließ. Durch einmaliges Umkristallisieren aus wenig heißer Salzsäure erhielten wir stets ein prächtig kristallisiertes, farbloses Präparat. Meist war die Abscheidung sofort eine vollständige und nur in einzelnen Fällen konnte durch Einengen der Mutterlauge und nochmaliges Einleiten von Salzsäure noch weitere Glutaminsäure gewonnen werden. Wir haben uns durch Entfernen der Salzsäure in einer Probe der Mutterlauge und die sehr scharfe Geschmacksprobe und auch in einem Falle mit Hilfe der Estermethode überzeugt, daß bis auf Spuren bei sorgfältigem Arbeiten die Glutaminsäure als Chlorhydrat abgeschieden werden kann. Sehr wichtig sind zwei Punkte. Einmal darf die Lösung nicht zu stark eingeengt sein. Sie darf keinen dicken, zähen Sirup bilden, andererseits ist oft auch ein zu reichlicher Salzsäuregehalt der Lösung anscheinend der Kristallisation hinderlich. Wir mußten uns vorläufig auf Tyrosin und Glutaminsäure ${ }^{1}$ )

1) Die Reinheit der isolierten Glutaminsäure wurde einesteils durch Bestimmung des Aschengehaltes, anderenteils durch die Analyse festgestellt. 
Über Assimilation des Nahrungseiweiß im tierischen Organismus. 197

beschränken, weil nur diese beiden Aminosäuren eine rasche und bequeme quantitative Bestimmung zulassen. Die «Hexonbasen» haben wir deshalb nicht mitbestimmt, weil uns der Gehalt des Gliadins und der Serumeiweißkörper an diesen unbekannt war.

Bevor wir auf die einzelnen Versuche eingehen, sprechen wir auch an dieser Stelle Herrn Prof. Dr. Ostertag, Vorsteher des hygienischen Institutes der tierärztlichen Hochschule, unseren herzlichsten Dank für die liebenswürdige Überlassung des Versuchstieres aus. Sehr zu Dank verpflichtet sind wir auch den Herren Assistenten Dr. Steinbrück und Dr. Tietze, die uns beide bei unseren Versuchen die wertvollsten Dienste geleistet haben.

Das Versuchstier, ein brauner Wallach, war 18 Jahre alt. Während der ganzen Versuchsdauer nahm es fast gar kein Wasser auf, auch nicht nach den Blutentnahmen. Letztere vertrug es sehr gut. Die Fütterung wurde in der Weise vorgenommen, daß das Gliadin zu großen Pillen gedreht und mit dem Pillenstock eingeführt wurde. Das Tier gewöhnte sich rasch an diese Fütterungsart.

Die folgende Tabelle gibt einen Überblick über die ganze Art des Versuches.

Versuch I.

\begin{tabular}{|c|c|c|c|c|c|c|c|}
\hline Datum & $\begin{array}{l}\text { Ge- } \\
\text { wicht }\end{array}$ & $\mid \begin{array}{c}\text { Stunde } \\
\text { des } \\
\text { Ader- } \\
\text { lasses }\end{array}$ & $\begin{array}{c}\text { Menge des } \\
\text { entnom- } \\
\text { menen } \\
\text { Blutes }\end{array}$ & $\begin{array}{c}\text { Er- } \\
\text { năhrung }\end{array}$ & $\begin{array}{c}\text { Stunde } \\
\text { der } \\
\text { Fütterung }\end{array}$ & $\begin{array}{c}\text { Menge } \\
\text { Nahrung }\end{array}$ & \\
\hline 28. VI. & $\left(326 \mathrm{~kg}^{1}\right)$ & $\left|\begin{array}{c}11 \mathrm{Uhr} \\
\text { früh }\end{array}\right|$ & 6000 & - & $\mid \begin{array}{c}\text { Absol.Hunger } \\
\text { bis 6. VII. }\end{array}$ & $\left|\begin{array}{l}\text { Wenig Wasser } \\
\text { aufgenommen }\end{array}\right|$ & I \\
\hline 6. VII. & $288 \mathrm{~kg}$ & $\begin{array}{l}9 \mathrm{Uhr} \\
\text { früh }\end{array}$ & 6000 & Gliadin & $\begin{array}{c}10 \mathrm{Uhr} \\
5\end{array}$ & $\begin{array}{l}500 \mathrm{~g} \\
1000 \text { ? }\end{array}$ & II \\
\hline 7. VII. & $277 \mathrm{~kg}$ & $\left|\begin{array}{c}10 \mathrm{Uhr} \\
\text { früh }\end{array}\right|$ & 4000 & Gliadin & $\begin{array}{c}11 \mathrm{Uhr} \\
5 \text { bis } 7 \text { Uhr }\end{array}$ & $\begin{array}{r}500 \mathrm{~g} \\
1000\end{array}$ & III \\
\hline 8. VII. & $272 \mathrm{~kg}$ & $\left|\begin{array}{c}9^{1} / 8 \mathrm{Uhr} \\
\text { früh }\end{array}\right|$ & 3500 & - & - & - & IV \\
\hline
\end{tabular}

1) Etwas zu hoch, weil das Tier noch beschlagen war. 
Versuch II.

\begin{tabular}{|c|c|c|c|c|c|c|c|}
\hline Datum & $\begin{array}{l}\text { Ge- } \\
\text { wicht }\end{array}$ & $\mid \begin{array}{c}\text { Stunde } \\
\text { des } \\
\text { Ader- } \\
\text { lasses }\end{array}$ & $\left|\begin{array}{c}\text { Menge des } \\
\text { entnom- } \\
\text { menen } \\
\text { Blutes }\end{array}\right|$ & $\begin{array}{c}\text { Er- } \\
\text { nährung }\end{array}$ & $\begin{array}{c}\text { Stunde } \\
\text { der } \\
\text { Fütterung }\end{array}$ & $\begin{array}{c}\text { Menge } \\
\text { Nahrung }\end{array}$ & \\
\hline 20. VII. & $305 \mathrm{~kg}$ & $\begin{array}{c}9 \mathrm{Uhr} \\
\text { früh }\end{array}$ & 6000 & - & $\begin{array}{l}\text { Hunger } \\
\text { bis 26. VII. }\end{array}$ & - & I \\
\hline 26. VII. & $272 \mathrm{~kg}$ & $\left|\begin{array}{c}9 \mathrm{Uhr} \\
\text { früh }\end{array}\right|$ & 5000 & Gliadin & $10 \mathrm{Uhr}$ & $1000 \mathrm{~g}$ & II \\
\hline 27. VII. & - & - & - & Gliadin & $\begin{array}{l}11 \text { Uhr früh } \\
5 \text { Uhr }\end{array}$ & $\begin{array}{r}500 \mathrm{~g} \\
1000 \stackrel{8}{ } \\
\end{array}$ & \\
\hline 28. VII. & $269 \mathrm{~kg}$ & $\left|\begin{array}{c}91 / 2 \mathrm{Uhr} \\
\text { früh }\end{array}\right|$ & 4000 & - & - & - & III \\
\hline
\end{tabular}

Während des I. und II. Versuches erhielt das Pferd gewöhnliches Futter. Das Blut wurde aus der Jugularis entnommen und in hohen Zylindern aufgefangen, dann auf Eis das Serum zur Abscheidung gebracht. Zur Vermeidung der Gerinnung wurde Ammoniumoxalat zugesetzt. Bei beiden Versuchen wurde jeweilen in einer aliquoten Menge des Serums der gesamte Eiweißgehalt bestimmt, ferner der Trockenrückstand und der Aschengehalt. Beim zweiten Versuch wurde außerdem der Gehalt an Globulin und Albumin festgestellt. Das gesamte Eiweiß wurde durch sorgfältiges Koagulieren mit Essigsäure bestimmt. Zur Bestimmung des Trockenrückstandes dampften wir jeweilen $10 \mathrm{ccm}$ ein und trockneten den Rückstand solange bei $115^{\circ}$, bis er konstantes Gewicht hatte. Dieser Rückstand diente auch zur Aschebestimmung. Albumin und Globulin wurden durch Halbsättigung mit neutraler, gesättigter Ammonsulfatlösung getrennt.

Die auf S. 199 folgende Tabelle gibt die erhaltenen Resultate wieder.

Es war nun auch von großem Interesse, die Frage zu entscheiden, ob im Serum unter so denkbar günstigen Bedingungen Eiweißabbauprodukte aufzufinden waren. In erster Linie fahndeten wir auf Albumosen. Es ist klar, daß bei der Koagulation so großer Serummassen auch bei großer Verdünnung mit Essigsäure und Hitze es nicht gelingen konnte, jede Spur 
Über Assimilation des Nahrungseiweiß im tierischen Organismus. 199

von Eiweiß zur Ausfällung zu bringen. In der Tat gab denn auch das Filtrat vom koagulierten, durch ein Koliertuch gepreßten Eiweiß deutlich alle Eiweißreaktionen. Wurde jedoch durch Zusatz von $10 \%$ Kochsalz die Koagulation unter stetiger Kontrolle der Reaktion ausgeführt oder wurden z. B. $250 \mathrm{ccm}$ Serum (III) mit der vierfachen Menge Wasser verdünnt, dann die Hauptmenge des Eiweißes durch Koagulation entfernt, und das Filtrat mit Bleicarbonat und Bleiacetat gekocht, so zeigte die filtrierte, von Bleisalzen befreite, im Vacuum stark eingeengte Flüssigkeit keine Spur einer Biuretreaktion und auch die übrigen Reaktionen auf Albumosen fielen vollständig negativ aus. Herr Dr. Teruuchi ist mit der Prüfung auf andere Eiweißabkömmlinge beschäftigt.

\begin{tabular}{c|c|c|c|c|c|c|c}
\hline \hline $\begin{array}{c}\text { 10 ccm Serum } \\
\text { enthalten }\end{array}$ & \multicolumn{4}{|c|}{ Versuch I } & \multicolumn{3}{|c}{ Versuch II } \\
\cline { 2 - 7 } \cline { 3 - 7 } & I & II & III & IV & I & II & III \\
\hline Gesamt-Eiweil . . & 0,7702 & 0,9278 & 0,7261 & 0,7492 & 0,7108 & 0,9436 & 0,7966 \\
Trockensubstanz . & 0,9132 & 1,0150 & 0,8359 & 0,9269 & 0,8120 & 1,0228 & 0,9246 \\
Asche ...... & 0,1002 & 0,0806 & 0,1043 & 0,1727 & 0,0812 & 0,0800 & 0,1326 \\
Albumin ..... & - & - & - & - & 0,2691 & 0,3054 & 0,2921 \\
Globulin ..... & - & - & - & - & 0,4212 & 0,6734 & 0,4232
\end{tabular}
Resultate:

Die Tyrosin- und Glutaminsäurebestimmung ergab folgende

\begin{tabular}{|c|c|c|c|c|c|c|c|}
\hline & \multicolumn{4}{|c|}{ Versuch I } & \multicolumn{3}{|c|}{ Versuch II } \\
\hline & I & II & III & IV & I & II & III \\
\hline & $\%$ & $\%$ & $\%$ & $\%$ & $\%$ & $\%$ & $\%$ \\
\hline Tyrosin & 2,43 & 2,60 & 2,24 & 2,52 & 2,50 & 2,55 & 2,48 \\
\hline Glutaminsäure . & 8,85 & 8,20 & 7,88 & 8,25 & 9,52 & 8,52 & 8,00 \\
\hline
\end{tabular}

Aus diesen Zahlen geht hervor, daß ganz offenbar die Art des zugeführten Eiweißes ganz ohne Einfluß auf das Serumeiweiß ist. Es muß somit an irgend einer Stelle eine Umwandlung des «Gliadins» stattgefunden haben. Es scheint 
200 Abderhalden und Samuely, Uther Nahrungseiweiß.

uns nicht unmöglich, daß die Leber bei diesen Prozessen eine Rolle spielt, für viel wahrscheinlicher halten wir eine direkte Umwandlung nach der Resorption des zum Teil abgebauten Eiweißes in der Darmwand. Es wäre wohl denkbar, daß in diesem Falle bereits im Darme unter Einwirkung des Pankreasfermentes ein Teil der Glutaminsäure abgespalten und vielleicht als solche resorbiert und weiter verwertet oder direkt verbrannt worden ist, während das nun an Glutaminsäure ärmere und natürlich auch noch in anderer Weise veränderte Eiweiß zur Resorption gelangt und zugleich «körpereigen» geworden ist. 